\title{
Die einstimmigen lateinischen Messgesänge in der Reformations- und Gegenreformationszeit in Mähren und deren liturgischer Betrieb
}

\section{Latin Mass Plainchant in Moravia in the Time of Czech Reformation and Counter-Reformation and their Liturgical Practice}

Stanislav Červenka / cervenka.S@seznam.cz

soukromý vědec

\begin{abstract}
The author carries out external and internal analyses of two in Moravia newly discovered Latin Utraquist Graduals from the beginnings of the sixteenth century and of another two Catholic Graduals from the end of the fifteenth century, which were also in practice in the reformation milieu of sixteenth century. On the basis of repertory collations, he determines their liturgical provenience and accomplishes their local and chronological registration. He observes their particularities and dissimilarities and catalogues them into a wider historical context. By making use of various posterior records and complements, he specifies the function of Graduals in liturgical practice in the time of Reformation and the subsequent Counter-Reformation.
\end{abstract}

\section{Key words}

Latin, mass, plainchant, practice, Utraquists, Catholicism, reformation, counter-reformation, Moravia 
Die musikwissenschaftliche Forschung der Reformationszeit in Mähren liegt immer noch am Anfang. Einerseits aufgrund der fehlenden Quellen im Vergleich zu Böhmen, anderseits wegen des schwachen Interesses der Forscher. Mein Beitrag befasst sich mit zwei Gradualien der lateinischen Utraquisten in Mähren aus dem Anfang des 16. Jahrhunderts, die ich vor kurzem entdeckte, und mit zwei katholischen Gradualien aus dem Ende des 15. Jahrhunderts mit Spuren der Reformationszeit. Fast alle vier Handschriften wurden auch im katholischen Gottesdienst der folgenden Jahrhunderte verwendet. ${ }^{1}$

Jede liturgische Handschrift stellt eine komplizierte Beziehungsstruktur der äußeren und inneren Merkmale dar, die eine Aussage über ihre liturgische Funktion, über Zeit und Ort ihrer Entstehung und ihres Gebrauches bieten. Es ist auch nötig jede Handschrift einer kodikologischen Analyse zu unterziehen. Regionale Interessen in der Tschechischen Republik fordern die Unterscheidung der partikularen Liturgien der Olmützer und der Prager Diözesen. Ohne Antwort auf alle diese Fragen verliert die Musikquelle an ihrer historischen Aussage. Für die Bestimmung der liturgischen und lokalen Herkunft jedes Graduale ist es wichtig die Individualität des Kyriale Repertoires, der Alleluia-Gesänge, der Sequenzen, Weihen- und Prozessionsriten und Feiertage der Heiligen zu untersuchen. Alle diese Formen entwickelten sich noch im Spätmittelalter auf eigene Weise. Aus diesem Grunde werde ich im meinen Beitrag auch diese Merkmale berücksichtigen.

Das Graduale aus Odry (Odrau), Biskupství Ostrava, fond Odry, sign. A: 40/80112/20/0250, wurde der Datierung auf Fol. 82r im Jahre 1504 geschrieben. ${ }^{2}$ Es ist das Graduale der lateinischen Utraquisten, dessen Struktur und Ordnung sich denen in den katholischen Gradualien ähnelt. Die Handschrift ist mehrmals beschädigt. Es fehlen zweite Teile der beiden Sanctoralen, das ganze Sequenziar, und die für die Stadtgemeinde wichtigen Marienmessen, Seelen- und Totenmessen, und auch Fronleichnamsmessen.

Das Kyriale-Repertoire folgt der schriftlichen Tradition der Olmützer Diözese seiner Zeit, d. h. nach der liturgischen Reform des Bischofs Jan ze Středy (Johanns von Neumarkt) im Jahre 1376. ${ }^{3}$ Es stimmen Melodienpaare Kyrie-Gloria und Sanctus-Agnus überein und auch die regelmäßige Auswahl der tropierten Kyrie- und Gloria-Melodien. ${ }^{4}$

1 In Olmützer Diözese wird aus dem 15. Jahrhundert noch ein zweibändiges Graduale überliefert, Archiv města Brna, fond V 2, sign. 1 und 2, das aber keine Spuren der Reformationszeit aufweist.

2 Vgl. auch TOŠNEROVÁ, Marie. Rukopisné fondy centrálních a církevnich knihoven v České republice. Praha 2004, S. 350. Weiter GRAHAM, Barry Frederic Hunter. Bohemian and Moravian Graduals 1420-1620. Turnhout 2006 , S. 311.

3 Der Olmützer Bischof Jan ze Středy verwirklichte im Jahre 1376 eine gründliche Reform der Liturgie und des liturgischen Gesanges in der Olmützer Diözese, die in seinem Liber ordinarius ecclesiae Olomucensis (Rubrica ecclesie Olomucensis) beschrieben wurde, Zemský archiv Opava (weiter ZAO), pobočka Olomouc, sbírka rukopisů Metropolitní kapituly sv. Václava v Olomouci (weiter MKO), sign. CO 15. Die Olmützer Handschriften vor dem Jahre 1376 verzeichnen die noch nicht stabilisierte Olmützer Tradition.

4 Seit 1376 verfügt die Olmützer Diözese regelmäßig nur über drei tropierte Kyrie: Fons bonitatis, Cunctipotens genitor, Magne deus potencie (MELNICKI 48, 18, 78) und ein tropiertes Gloria: Spiritus et alme orphanorum paraclite (BOSSE 23). Die Melodien des Ordinariums Missae werden nach den deutschen Katalogen zitiert: MELNICKI, Margareta. Das einstimmige Kyrie des lateinischen Mittealters. Regensburg 1955. BOSSE, Detlev. Untersuchung einstimmiger mittelalterlichen Melodien zur Gloria in excelsis Deo. Regensburg 1955. Thannabaur, Peter Josef. Das einstimmige Sanctus der römischen Messe in der handschriftlichen Überlieferung vom 
Es gibt nur einige Ausnahmen: auf Fol. 1v ist Kyrie Melnicki 89 notiert, das in den Gradualien der lateinischen Utraquisten in Böhmen früher belegt wird. ${ }^{5}$ Auf Fol. 12r wird tropiertes Sanctus Thannabaur 182, Benedictus Caste matris fructus ${ }^{6}$ und auf Fol. 11v tropiertes Agnus Schildbach 160, Miserere Deus vere nobis dere bezeichnet. ${ }^{7}$ Auf Fol. 9v hinter dem Sanctus Thannabaur 185, wird der Text des lateinischen Cantio Iesus Christus nostra salus aufgezeichnet, der aus vorhussitischer Zeit stammt, am frühesten im Gesangbuch aus Vyšší Brod (Hohenfurt) erscheint. ${ }^{8}$ Hinter das letzte Agnus, Schildbach 198, wird zweistimmiges Cantio Vivus panis angelorum angelegt, mit der frühesten Eintragung im Graduale aus Jistebnice (Jistebnicz). ${ }^{9}$ Beide Gesänge De Corpore Christi waren bei lateinischen Utraquisten beliebt. ${ }^{10}$

Nach dem Kyriale folgen noch vier Texte der lateinischen Mariencantiones und zwei Mariensequenzen, alle für den Advent bestimmt. Darunter steht an erster Stelle eine unbekannte Sequenz Ave salus peccatorum, revelatrix sis lapsorum. ${ }^{11}$ Die zweite Sequenz Ave virgo gloriosa / celi iubar ist des dominikanischen Ursprungs und stammt aus dem 13. Jahrhundert. ${ }^{12}$ Weiter sind noch vier Texte der Mariencantiones vorhanden, die auch für den Advent bestimmt sind. Zwei Cantiones sind aus der vorhussitischer Zeit: Ad honorem et decorem und Ave maris stella / lucens, beide aus dem Gesangbuch von Vyšší Brod (Hohenfurt) $\mathrm{H} 42$ bekannt. ${ }^{13}$ Zwei andere Cantiones $O$ regina lux divina und En emola tipica

10. bis zum 16. Jahrhundert. Erlangen 1962. Schildbach, Martin. Das einstimmige Agnus Dei und seine handschriftliche Überlieferung vom 10. bis zum 16. Jahrhundert. Erlangen 1967. Es wird zitiert: Gesangsname, Nummer des Katalogs (z.B. Kyrie, MELNICKI 89). Vgl. auch ČERVENKA, Stanislav. Zpěvy mešního ordinaria v nejstarších rukpisech Metropolitní kapituly Olomouc, jejich identifikace a historické ocenění. In Kritické edice hudebnich památek VII. Hudba v Olomouci. Historie a současnost II. In honorem Robert Smetana. Olomouc 2004, S. 124-144.

5 Z. B. im Messgesangbuch aus Kutná Hora (Kuttenberg) aus 15. Jahrhundert, Österreichische Nationalbibliothek Wien, Sign. 15501, auch im Franus Gesangbuch aus 1505, Muzeum Východních Čech, Hradec Králové (weiter HKm), sign. II A 6. Die Melodie ist seit dem 15. Jahrhundert auch in den deutschen Quellen bekannt, MELNICKI 1954, S. 52.

6 Dieses Tropus fehlt bei VLHOVÁ-WÖRNER, Hana. Tropi Ordinarii Missae, Pars III. Sanctus. Praha: Editio Bärenreiter, 2010.

7 VlHOVÁ-WÖRnER, Hana. Tropi Ordinarii Missae, Pars IV. Agnus. Praha: Editio Bärenreiter, 2013, S. 68-69. Text AgTr 7, S. 97-104 Melodie AgTr 7.

8 Vyšší Brod, Klášterní knihovna (weiter VBKk), sign. H 42. Dreves, Guido Maria. Analecta hymnica medii aevi Bd. 45b, Lider und Motetten des Mittelalters. Leipzig 1904, S. 105, Nummer 125. Editiones auch NEJEDLÝ, Zdeněk. Dějiny husitského zpěvu. Kniha třeti Jan Hus. Praha 1955, S. 132-135, S. 408-409; OREL, Dobroslav. Kancionál Fránusưv z roku 1505. Praha 1922, S. 108.

9 Graduale aus Jistebnice, zweite Hälfte des 15. Jahrhunderts, Knihovna Národního muzea Praha (weiter PNm), sign. XII F 14. Vgl. Op. cit. AH 1, S. 147, Num. 144. Editio OREL, op. cit., 1922, S. 109.

10 Vgl. OREL, op. cit., 1922, S. 138.

11 Diesen Text ist nirgendwo zu finden, seinen Ursprung muss noch nachgeprüft werden.

12 BLUME, Clemens - BANNISTER, Henry Marriott. Analecta hymnica medii aevi Bd. 54. Liturgische Prosen des Übergangsstiles und der zweiten Epoche (weiter AH 54). Leipzig 1914, S. 417-418, Num. 277.

13 DREVES, Guido Maria. Analecta hymnica medii aevi Bd. 1. Cantiones Bohemice. Leiche, Lieder und Rufe des 13., 14., und 15. Jahrhundrts nach Handschriften aus Prag, Jistebnicz, Wittingau, Hohenfurt und Tegernse (weiter AH 1). Leipzig 1886, S. 47, Num. 1 (Ad honorem), S. 49, Num. 4 (Ave maris stella lucens). Editio bei OREL 1922 , S. 61-62 (Ad honorem), S. 62-63 (Ave maris stella). 
sind am frühesten im Graduale aus Jistebnicz (Jistebnice) aufgenommen. ${ }^{14}$ Auch dieser Abschnitt bezeichnet das übliche Adventrepertoire der lateinischen Utraquisten und gehört schon in der Handschrift zu dem Folgen Advent des Temporale.

Im Temporale lassen fast alle Feiertage und Sonntage den Gradualegesang aus, doch nicht systematisch. Alle Sonntage und Alltage der Fastenzeit bis Gründonnerstag und Ostersonntag mit Osterwoche führen den Gradualegesang ein. Den Rest des Temporale und der ganzen Sanctorale und Commune sanctorum Gradualegesänge lassen sie aus. ${ }^{15}$

Das Alleluiarepertoire folgt der Überlieferung der Olmützer Kirche aus der Mitte des 14. Jahrhunderts, das heißt noch vor der Reform in $1376 .{ }^{16}$ Auch Weihen- und Prozessionsriten des Graduales folgen der Olmützer Überlieferung vor der Reform, aber nur in verkürzter Auswahl für eine kleinere Stadt. ${ }^{17}$ Sie setzen noch ein weiteres liturgisches Buch die Agenda vor, wie es die Rubrik, Fol. 68r, „patet scriptum agenda“ des Palmsonntags bezeugt. Am Karfreitag, Fol. 75v-77v, wurden die singenden Personen des liturgischen Betriebs eingetragen: „Tribus pueris“ singen das griechische Trisagion „Agios o theos“, Chorus antwortet lateinisch „Sanctus deus“. Das bestätigt die Existenz der lateinischen Schule in Odry, und auch des Chores, wie in späteren Quellen nachgewiesen ist. ${ }^{18}$

Das Graduale aus Odry verfügt über zwei Sanctoralen, ${ }^{19}$ in beiden fehlt jedoch die zweite Hälfte des liturgischen Jahres. Sie bezeichnen auch den Entwicklungsstand der Mitte des 14. Jahrhunderts. Das zweite Sanctorale ist dabei wichtiger wegen einem Eintrag des Festes auf dem Fol. 138v, Decem milia militum martyrum (22. Juni). Das Fest führte Karl IV. im Jahre 1352 in der Prager Kathedrale ein, ${ }^{20}$ womit die Datierung der Vorlage dieses Graduale ermöglicht wurde. Verschiedene Nachträge und Berichtigungen bestätigen den liturgischen Betrieb jeder Handschrift. Im Kyriale wurde bei zwei Gloriagesängen, Fol. 2rv - Gloria Bosse 24, Fol. 8v - 9r - Gloria Bosse 48, die Verteilung zwischen dem Organisten und dem Chorus im 16. Jahrhundert bezeichnet. Der Odrauer Historiker Rolleder weist auf eine Nachricht über die Orgelreparatur im Jahre 1556

14 Graduale aus Jistebnice, PNm XII F 14. Vgl. op. cit. AH 1, S. 82, Num. 42 (O regina lux divina), S. 63, Num. 21 (En emola tipica). Editio bei OREL, op. cit., 1922, S. 74-75 (O regina lux divina), S. 68 (En emola typica).

15 Vgl. OREL, 1922, op. cit., S. 51.

16 Die Alleluiaverse der Osterzeit und der Sonntage nach den Pfingsten dienen der Lokalisierung und der Datierung der Handschriften, vgl. SCHLAGER, Karlheinz. Thematischer Katalog der ältesten Alleluia-Melodien aus Handschriften des 10. und 11. Jahrhunderts, ausgenommen des ambrosianische, altrömische und alt spanische Repertoire. Verlegt bei Walter Riecke, München 1965, S. 17, Anm. 65, wo auch weitere Werke notiert werden. Vgl. auch Anm. 3.

17 Die Auswahl von Gesängen stimmt mit dem Olmützer Vollmissale aus der Vorreformzeit überein, ZAO, pobočka Olomouc, MKO, sign. CO 141.

18 Die Nachricht über die Odrauer Schule im Jahre 1547 vgl. ROLLEDER, Anton. Geschichte der Stadt und des Gerichtbezirkes Odrau. Steyer 1903, S. 159-160.

19 Das erste Sanctorale, Fol. 120v-127v, notiert nur Gesänge für die wichtigsten Feste des Proprium sanctorum von In vigilia Andree bis In vigilia Petri et Pauli, noch mit Unterbrechungen der ausgerissenen Folia. Das zweite Sanctorale, Fol. 138v, bezeichnet nur Textanfänge der Gesänge des Proprium sanctorum ab Andree bis Johannis Baptistae mit Hinweisen auf Folia im Commune sanctorum.

20 In Olmützer Diözese ist der erste Eintrag des Festes im Missale Olomucense nach der Mitte des 14. Jahrhunderts, ZAO pobočka Olomouc, MKO, CO 131. 
hin. ${ }^{21}$ Im Kyriale, Fol. 2rv, gibt es einen Versuch der deutschen Übersetzung des Glorias in excelsis: „Ere sey Gott in den hechsten ...", und im Temporale, Fol. 17rv, noch Übersetzung des Alleluia Ostende nobis für den ersten Adventssonntag: „Herz zeug uns deine barm herz ..... Beide Übersetzungen dokumentieren die Einflüsse der Lutheraner in Odry in der zweiten Hälfte des 16. Jahrhunderts. Den Betrieb des Graduales im 17. Jahrhundert beachten z.B. die häufigen Ausführungen der gotischen Abbreviaturen und auch die Ergänzungen der ausgelassenen Gradualengesänge an Sonntagen nach den Pfingsten.

Odry war eine Untertanenstadt. Im Jahre 1504 herrschte dort Jeroným II. aus Odrau und Luderow (Odry und Ludéřov). Als Anhänger von Georg von Podiebrad (Jiří z Poděbrad) war er utraquistisch orientiert. Er pflegte nicht nur wirtschaftliche, sondern auch kirchliche Fortentwicklung seines Herrschaftsgutes. ${ }^{22}$ Deshalb konnte er auch Graduale für den Gottesdienst in der St.-Bartholomäus-Kirche anfertigen lassen. Seit 1519 herrschten in Odry die Herren von Fullstein (z Fulštejna) und dann zwischen 1533 und 1612 saßen hier die Herren von Zwola (ze Zvole), die zur protestantischen Gemeinde gehörten. Während ihrer Herrschaft wirkten elf evangelische Pastoren in Odry und dann unter Herrschaft der Adelsfamilie Praschma (Pražma) noch zwei. ${ }^{23}$ Welche liturgischen Bücher sie benutzten, ist nicht bekannt. Der Einbandseinschrift nach wurde das vernichtete Graduale im Jahre 1582 mit einem neuen Einband versehen. ${ }^{24}$ Infolge dessen überlebte das Graduale bis in das Jahr 1628, und konnte nach den Korrekturen dem katholischen Gottesdienst dienen. ${ }^{25}$

Das zweite Papiergraduale, Vědecká knihovna Olomouc, sign. M II 398, wird mit Schriftkorrosion sehr schwer beschädigt, und vom Zerfall bedroht. ${ }^{26}$ Nach äußerem Aussehen schätze ich es für den Anfang des 16. Jahrhunderts ab. Dem liturgischen Inhalt nach ist das wieder lateinisches Graduale der Utraquisten, besser gesagt nur ein Gradualeauszug.

Der Anfang des Kyriale-Repertoires, Fol. Ir-Xv, ist umfangreich beschädigt. Alle übriggebliebenen Melodien sind im 16. Jahrhundert in der Prager und der Olmützer Diözese ganz üblich. Bemerkenswert ist nur die Kyrie-Melodie Melnicki 163, die in Olmütz nicht eingetragen ist. Sie ist mit den Melodien Sanctus Thannabaur 132, und Agnus Schildbach 194 in den Handschriften der Böhmischen Utraquisten komplementär.

Das Temporale, Fol. 1r-56v, vermerkt nur Hauptfeste und Sonntage des Kirchenjahres. Alle Sonntage nach den Pfingsten werden ausgelassen. Der Gradualegesang wird nur bei der Rorate-Messe im Advent, am Gründonnerstag, am Ostersonntag, -montag und

21 Op. cit. Rolleder 1903, S. 149, den Gemeinderechnungen nach renovierte 1556 den Blasbalken bei Orgel der Organist Merken Nipel.

22 Ibid., S. 66-76.

23 Ibid., S. 155-156. Auch WOLNY, Gregor. Kirchliche Topographie von Mähren, meist nach Urkunden und Handschriften. I. Abteilung Olmützer Erzdiöcese. I. Band. Brünn 1855, S. 182 ist gegen Rolleder einer anderen Meinung über Zahl der Pastoren in Odry.

24 Der Einschrift nach auf dem vorderen Buchdeckel „PERTINET IN ECLE / SIAM ODERANAM / RENOVATUM ANNO 1582“.

25 Vgl. ROLLEDER, op. cit., 1903, S. 157.

26 Vgl. TOŠNEROVÁ, op. cit., 2004, S. 74. Weiter auch GRAHAM, op. cit., 2006, S. 297-299. 
-mittwoch bezeichnet. Gradualegesänge fehlen auch in dem ganzen Sanctorale und Commune sanctorum. Infolge des reduzierten Temporals können wir nicht eindeutig anwenden die Alleluia-Reihen zur Bestimmung ihres liturgischen Ursprungs. Aus Weihen- und Prozessionsriten nur am Palmsonntag die Palmweihe und folgende Prozessionsgesänge notiert werden, Fol. 35v-39v, beide der Prager Ritus mit Anfangsantiphon Osana filio David. ${ }^{27}$

Das Sanctorale, Fol. 58r-71r, vermittelt nur Auswahl der wichtigsten Heiligenfeste des Kirchenjahres. Erst das Sequenziar, Fol. 85r-129v, bringt Sequenzen und Alleluiagesänge für folgende Kirchenfeste: Visitatio S. Mariae, Margarete, Marie Magdalene, Nativitatis Marie, Omnium sanctorum. In einem mit derselben Hand geschriebenem Ergänzungsteil, Fol. 129v-137v, wurden noch Alleluia und Sequenzen der Heiligen Wenzeslaus, Ludmilla, Martinus, Nicolaus und Anna geschrieben. Obwohl die Sanctorale-Teile reicher an Festen sind, fehlen die wichtigsten Provenienz- und Datierungsmerkmale.

Nach Commune sanctorum, Fol. 71r-81r, werden noch Totenmesse Requiem eternam mit dem Gradualegesang Requiem, Alleluiagesänge für Marienmessen im Verlauf des Jahres bezeichnet. Am Ende der Handschrift, Fol. 142r-143v, wurden mit derselben Hand noch Fronleichnamsmessgesänge eingetragen: die Sequenz O panis dulcissime, die aus Süddeutschland des 13./14. Jahrhunderts stammt, ${ }^{28}$ und das Offertorium Sacerdotes incensum mit der Prosula Ave virgineum corpus domini. ${ }^{29}$

Den liturgischen Betrieb des Graduale bezeugen Zusätze aus folgender Zeit: auf dem letzten Folio wurde der Text des Cantio Mittitur archangelus fidelis bezeichnet, das dem Verfasser des Gesangbuches aus Vyšší Brod (Hohenfurt) bekannt wurde. ${ }^{30}$ In der zweiten Hälfte des 16. Jahrhunderts wurde von einer anderer Hand auf den hinteren Buchdeckelspiegel der Liedertext geschrieben: Zdrávas ..., jenž jsi pozdravena andèlem poslem od Boha. ${ }^{31}$ Auf dem vorderen Buchdeckelspiegel wurde im 16. Jahrhundert der Text des lateinischen Cantio Salve amicta sole sponsa eingetragen. ${ }^{32}$ Darunter wurde von einer anderen Hand des 16. oder 17. Jahrhunderts das katholische zugegebene Offizium De Passione Domini: Patris sapientia, veritas divina, geschrieben. ${ }^{33} \mathrm{Im} 16$. Jahrhundert wurden

27 Vgl. Liber ordinarius ecclesiae Pragensis, PNm XIV D 9, Fol. 26v „[...] tunc presbiter cum ministris, qui celebraturus est, indutus sollempni apparatu et cappa, accedens ad frondes incipit antiphonam Osanna filio david, quam chorus finit $[\ldots]^{\prime \prime}$.

28 BLUME - BANNISTER, op. cit., S. 259, Num. 169.

29 BLUME, Clemens. Analecta hymnica medii aevi Bd. 49. Tropen des Missale im Mittelalter II. Tropen zum Proprium Missarum. Leipzig 1906, S. 325, Num. 643, am frühesten im Graduale Admontense saeculo 15.

Vgl. auch VLHOVÁ, Hana. Die Fronleichnamsmesse in Böhmen: Ein Beitrag zur spätmittelalterlichen Choraltradition. Schweizer Jahrbuch für Musikwissenschaft 1996, S. 13-36, in dem gibt es auf dieselbe Melodie ein anderer Prosula-Text Ave salus Cristianorum.

30 Vgl. VBKk H 42. AH 1, op. cit., S. 123, Num. 104.

31 Vgl. JIREČEK, Josef. Hymnologia Bohemica. Dějiny církevního básnictvi až do 18. století. Praha, 1878, S. 85. Auch KONRÁD, Karel. Dějiny posvátného zpěvu staročeského od XV. věku do zrušeni literátských bratrstev. Praha, 1893, S. 102-103.

32 Vgl. AH 1, op. cit., S. 134, Num. 122.

33 Vgl. DREVES, Guido Maria. Analecta hymnica medii aevi Bd. 30. Pia dictamina. Reimgebete und Lieder des Mittelalters. Leipzig, 1898, S. 32-35, Num. 13. 
noch drei andere tschechische Bemerkungen ins Graduale notiert. ${ }^{34}$ Ergänzungen im 16. und 17. Jahrhundert bestätigen nur einen schwachen liturgischen Betrieb dieses Graduale in dieser Zeitspanne.

Dieses Graduale stammt ursprünglich aus der Klosterbibliothek der FranziskanerObservanten in Ungarisch Hradisch (Uherské Hradiště). Es handelt sich um den lateinischen utraquistischen Gradualeauszug des weltlichen Ritus der Prager liturgischen Provenienz. Dem Inhalt nach wurde das Graduale etwa für eine kleine Stadt in der Umgebung von Uherské Hradiště zusammengestellt. ${ }^{35}$ Nach dem Besitzereintrag auf Fol. IIr "Convetus Hradistiensis Fratrum Minorum 1760" könnte das Graduale aus der früheren Lokalität in die Konventsbibliothek durch einen Franziskanerpriester gebracht werden, der zur Zeit des Siebenjährigen Krieges (1757-1764) in den vom Krieg bedrohten Städten anstatt der entflohenen Priester die geistliche Fürsorge pflegte. ${ }^{36}$ Denselben Besitzereintrag gibt es auch in einer anderen Handschrift dieser Konventsbibliothek. ${ }^{37}$ František Pokorný wies in seinem Artikel auf die wichtigen hussitischen Zusätze der Karfreitags- und Samstagsriten hin. ${ }^{38}$

Das dritte Graduale ist katholisch und wird jetzt in dem Muzeum Brněnska, Památník písemnictví na Moravě, Rajhrad, sign. R 627 aufbewahrt. ${ }^{39}$ Es stammt aus Mährisch Trübau (Moravská Třebová). Den Repertorien und der äußeren Charakteristik nach schätze ich es in die 90er Jahre des 15. Jahrhunderts. Es umfasst Chorgesänge für die Messe in der partikularen Olmützer Liturgie nach der Reform des Bischofs Johann von Neumarkt (Jan ze Středy) im Jahre 1376. Diese Handschrift ist am Anfang und am Ende beschädigt.

Alle Melodien des Kyriale, Fol. 1r-13v, entsprechen der Olmützer Tradition seiner Zeit. Das letzte Melodiepaar, Sanctus Thannabur 194, mit Agnus Schildbach 243, ist vereinzelt (singulär). Beide deutschen Kataloge verzeichnen dieselben Melodien frühestens in dem St. Gallener Sammelband des Fraters Joachim Cuonz 1507. ${ }^{40}$

Die Alleluiagesänge des Temporale, Fol. 15r-156v, folgen auch der liturgischen Reform Johanns von Neumarkt. Dasselbe kann man auch über die Weihen- und Prozessionsgesänge sagen. Den Karfreitagsimproperien, Fol. 108v-111r, wurden im 16. Jahrhundert singende Personen nachträglich beigefügt: duo pueri Agios o theos, chorus Sanctus deus, duo cantores Quia eduxi te, duo cantores Quid ultra. In Adoratione crucis: sacerdos Ecce

34 Vgl. Fol. Iv Federproben mit dem Text in der neogotischen Kursivschrift des 16. Jahrhundert „Ponewadz / gsem rzekl Panu / Yanowy memu / Mylemu Bratru /Rzkl ze“. Fol 57r „sem / P nonew adz sem Ponev“. Für das Lesen der neogotischen Texte danke ich dem Herrn Bohdan Kaňák. Noch eine tschechische Notiz wird auf Fol. 66 im St. Laurentius Messofficium „Zdravi stzesti vam vinsuji“ geschrieben.

35 Meiner Meinung nach aus Uherský Brod (Ungarisch Brod), Uherský Ostroh (Ungarisch Ostra), oder Bzenec (Bisenz).

36 Vgl. FOLTÝN, Dušan a kolektiv. Encyklopedie moravských a slezských kläšterů. Praha, 2005, S. 695.

37 Es handelt sich um Breviarium Pragense aus der zweiten Hälfte des 14. Jahrhunderts, jetzt auch in der Wissenschaftlichen Bibliothek Olmütz aufbewahrt, Sign. M I 719.

38 POKORNÝ, František. Breviarium Pragense rukopisu M I 719 Státni vědecké knihovny v Olomouci. Studie o rukopisech, 1971, roč. 10, S. 257-277.

39 Vgl. auch DOKOUPIL, Vladislav. Soupis rukopisů benediktinské knihovny v Rajhradě. Praha, 1966, S. 319320. Weiter auch GRAHAM, op. cit., 2006, S. 135-137.

40 St. Gallen, Stiftsbibliothek, Sign. 456. Vgl. THANNABAUR, op. cit., 1962, S. 192, Schildbach, 1967, S. 157. 
lignum crucis, chorus Venite adoremus. Das weist auf die lateinische Schule und den Chor im 16. Jahrhundert in Mährisch Trübau hin, wie schon Karel Konrád bemerkte. ${ }^{41}$

Das Sanktorale, Fol. 158r-182r, entspricht auch der Olmützer partikularen Überlieferung, dem Stand, der in dem Wiegendruck des Missale Olomucense, Bamberg 1488 bezeichnet wurde. ${ }^{42}$ Die Auswahl der Sanctoralefeste ist für eine kleinere Stadt bestimmt. Das St. Erasmusfest (3. Juni) wurde schon direkt eingetragen, bisher war es nur „extra rubricam“. Die Sanctorale-Feste Decem milia militum martyrum und der Schlesischen Schutzheiligen Hedwig gewidmeten propriale Alleluia, während die wichtigen Landesund Lokalpatrozinien, St. Wenzel ausgenommen, nur Alleluia de Communi haben, und die St. Adalbert, St. Veit und St. Prokop leider ohne Sequenzen geblieben sind. Bemerkenswert ist Visitatio S. Mariae (2. Juli): im Sanctorale, Fol. 174v, wird Alleluia Ave stillans melle, wie in der Prager Diözese bezeichnet, aber in Commune Marianum, Fol. 218r, wird Alleluia In Maria benignitas geschrieben, ${ }^{43}$ und im Sequenziar, Fol. 243v, ist die Sequenz Veni precelsa domina bezeichnet. Beide Gesänge stammen aus Deutschland des 14. Jahrhunderts, und in Olmütz wurden gegen Jenštejns Werke gegensätzlich gehalten. ${ }^{44}$

Auf den liturgischen Betrieb weisen folgende Zusätze hin: Nach Kyriale, Fol. 14rv, wird im 16. Jahrhundert lateinisches Credo geschrieben, beginnend mit Patrem Omnipotentem. ${ }^{45}$ Nach der Kirchenweihe, Fol. 157v, ist die tschechische Übertragung des Introitus für das Maria Magdalena Fest: Radujme se všickni v Pánu Ježiši vždycky. ${ }^{46}$ Seine Singweise entspricht dem Eintrag im Graduale, Muzeum Východních Čech, Hradec Králové, sign. Hr 57, aus den Jahren 1550-1553. ${ }^{47}$ Der dritte Fall ist die deutsche Übertragung der Weihnachtssequenz mit Rubrik „Das Grates nunc omnes Teutsch. Anno [15]84: Last uns nü alle dancsagendem herren Gott ...", was ein datierter Beweis für die deutsche Reformation in Moravská Třebová ist. Noch weitere Nachträge der singenden Personen wurden in der ersten Hälfte des 16. Jahrhunderts geschrieben: Fol. 38rv, Dominica in Quinquagesima der Tractus Iubilate deo, geteilt nach Verse Pueri - Literati - Chorus. Fol. 86v-87r, Dominica in Passione der Tractus Sepe expugnaverunt, geteilt Literati - Chorus. Alle diese Nachträge weisen auf die Existenz einer lateinischen Schule in Moravská Třebová und auch den Literatenchor hin. ${ }^{48}$ Der übliche Bestandteil der Handschriften des 16. Jahr-

41 KONRÁD, op. cit., 1893, S. 157.

42 Missale Olomucense, Bambergae, Johann Sensenschmidt imp. Petri Drach, IV. Non. Mart. [4. 3.] 1488.

43 SCHLAGER, Karlheinz. Monumenta monodica medii aevi, Bd. 8. Alleluia-Melodien ab 1100. Bärenreiter Kassel, Basel, London, New York 1987, S. 231.

44 op. cit. AH 54, S. 301, Num. 193.

45 Vgl. Kyriale seu ordinarium missae cum cantu gregoriano ex editione Vaticana adamussim excepto. Desclée et socii Parisiis, Tornaci, Romae 1920, Credo I., S. 57-60.

46 Auf ein leeres Folio hinter die Kirchenweihemesse wurde im 16. Jahrhundert der Anfang des tschechischen Introitus geschrieben, dessen Fortsetzung auf weiterem Folio ausgerissen ist.

47 Vgl. ŽŮREK, Jiří. Graduale Bohemorum, Proprium sanctorum. Praha, 2011, S. 156-157.

48 KONRÁD, op. cit., 1893, S. 157. Vgl. auch MAŇAS, Vladimír. Náboženská bratrstva do josefinských reforem. In JIRÁNEK, Tomáš - KUBEŠ, Jiří (edd.). Bratrstva. Světská a církevni sdružení a jejich role v kulturních a společenských strukturách od středověku do moderni doby. Pardubice, 2005, S. 45 nur Erwähnung über Literaten in Moravská Třebová. Vgl. auch RŮŽIČKA, Jindřich. Okresni archiv Svitavy se sidlem v Litomyšli. Průvodce po ar- 
hunderts sind auch drei datierte Erinnerungseinträge, alle aus der Zeroteinzeit. ${ }^{49}$ Auf Rückkehr zum katholischen Gottesdienst im 17. Jahrhundert weisen Berichtigungen und Verweisungszeichen von drei verschiedenen Schreibern in der ganzen Handschrift hin. ${ }^{50}$

Moravská Třebová war eine Untertanenstadt. Im Jahre 1486 kaufte diesen Adelsfamiliengut der Neffe des Olmützer Bischofs Tas von Boskowicz (z Boskovic), Ladislav Velen z Boskovic, der ursprünglich im geistlichen Stande wirkte, aber nach dem unglücklichen Tode seines Bruders Jaroslav das Familienvermögen übernahm. Er machte bald aus seinem Sitz Moravská Třebová eine wahre Renaissancestadt. Das Graduale wurde damals wahrscheinlich in seiner Schlossbibliothek aufbewahrt. ${ }^{51} \mathrm{Im}$ Jahre 1550 vertrieben Václav und Jan z Boskovic den katholischen Priester, um einen evangelischen Pastor einzusetzen. Bis 1622 wirkten sieben Pastoren in Moravská Třebová. ${ }^{52}$ Im Jahre 1582 übergab Jan z Boskovic das Besitzerrecht der Kirche an die Stadt. ${ }^{53}$ Zwischen den Jahren 1589 bis 1622 herrschte dort Ladislav Velen von Zerotin (z Žerotína), der nach der Schlacht auf dem Weißen Berg ins Ausland fliehen musste. Sein Vermögen gewann als Konfiskation Karl von Liechtenstein. Er fing die mit Rekatholisierung an. Bereits 1623 kam nach Moravská Třebová der erste katholische Priester. Im Jahre 1631 wurde von Liechtenstein eingeordnet, dass alle Bücher ins Pfarrhaus gebracht werden sollen. Hier wurde deren Inhalt von den Geistlichen nachgeprüft. Das Graduale blieb da bis $1853 .{ }^{54}$ In diesem Jahre schenkte es der Kooperator Franz Krönes den Benediktinern von Rajhrad, in dem das Graduale bis in die 50er Jahre des 20. Jahrhunderts blieb. ${ }^{55}$ Dann wurde es im Rahmen der Klostersäkularisierung in der Universitätsbibliothek in Brünn gebracht. Anfangs des 21. Jahrhunderts kehrte das Graduale nach Rajhrad zurück.

Das letzte katholische Graduale stammt aus Velká Bíteš (Groß Bitesch), jetzt in Městské muzeum Velká Bíteš, sign. C 1/7 aufbewahrt. ${ }^{56}$ Dem Inhalt nach kann ich es ans Ende des 15. Jahrhunderts schätzen. Graduale umfasst Chorgesänge der Messe in der partikularen Olmützer Liturgie nach der Reform des Bischofs Jan ze Středy im Jahre 1376

chivnich fondech a sbirkách. Praha, 1973, S. 127. Regesten der Urkunde aus 15. November 1514 von der Grundüberlassung der Konfraternität des Marienaltars.

49 Fol. 142r „PM 1591“, Fol. 173r „IW 1591“, Fol 255v „J.P.T.M. 1610“.

50 Z. B. vgl. Fol 17r alle drei Hände in margine, Fol. 111r-113r am Karsamstag Umgestaltung der Tractus.

51 Vgl. LIFKA, Bohumír. Staré knihovny v Moravské Třebové. In PECHOVÁ, Oliva (ed.). Moravská Třebová. Městská památková rezervace Státni památkové správy. Praha 1957, S. 46 „[...] díla rukopisná. O nich shledáváme rozptýlené zprávy, o kancionálech, vyzdobených malbami, iniciálami a rodovými boskovickými znaky [...]“. Vgl. weiter Grolig, Moritz. Die Bibliothek des Ladislaus von Bozkovicz (1485-1520) in Mährisch Trübau. Mitteilungen des österreichischen Vereines für Bibliothekswesen. 1904, S. 149-158. Im Verzeichnis, S. 154-156, aber diese Werke fehlen. Meiner Meinung nach musste Grolig bei seinem Besuch in Rajhrad (Raigern) diese Handschriften übersehen.

52 Vgl. Wolny 1855, S. 451, in dem eine andere Zahl geschrieben wird.

53 Vgl. RŮŽIČKA, op. cit., 1973, S. 128 die Regesten der Urkunde.

54 Vgl. LIFKA, op. cit., 1957, S. 47.

55 Ibid., S. 48.

56 Vgl. auch TOŠNEROVÁ, Marie. Rukopisné fondy muzei a galerii v České republice. Praha 2001, S. 183. Weiter GRAHAM, op. cit., 2006, S. 557-560. 
mit einigen Resten der Vorreformzeit. Die Handschrift ist in allen liturgischen Partien infolge der Folioverluste schwer beschädigt.

Das Kyriale-Repertoire, Fol. 1r-10v, erhielt sich bedauerlicherweise nicht in vollem Umfang. Die übriggebliebenen Kyrialemelodien stimmen mit den Handschriften der Olmützer Überlieferung ihrer Zeit überein. Die Alleluia-Reihen des Temporale, Fol. 11r-122v, folgen auch der liturgischen Reform Johanns von Neumarkt, ähnlich auch alle Weihen- und Prozessionsgesänge. Als Vorlage beim Abschreiben dieser Handschrift diente, meiner Ansicht nach, ein Graduale, das die Korrektur der Reform nicht konsequent ausgeführt hatte. ${ }^{57}$

Das Sanctorale, Fol. 123v-158v, ist am interessantesten, aber schwer beschädigt. Es fehlen die Feiertage seit dem 12. Mai bis zum 28. Juni und seit dem 22. August bis zum Ende des Kirchenjahres. Aus gebliebenen Alleluiagesängen des Sanctorale sind die Werke bemerkenswert, die in der Schlager-Edition Momumenta Monodica Medii Aevi, Band VIII nicht eingetragen sind: ${ }^{58}$ Dorotea (6. Februar) mit Alleluia O castitate phalerata, Anna (26. Juli) mit Alleluia Felix es sancta Anna, und Augustin (28. August) mit Alleluia Sidus splendidum magne pater Augustine. Auch das Sequenziar ist sehr beschädigt: es fehlen Sequenzen von Stephan bis den Heiligen Geist und dann von Johann dem Täufer bis ans Ende des Jahres. Bemerkenswert sind die Sequenzen: Für Conceptio sancte Marie (8. Dezember), Fol. 128v, Festum Marie venerantes; im Sanctorale gibt es nur Textincipit und im Sequeziar ist diese Sequenz herausgerissen. ${ }^{59}$ Noch weitere gebliebenen Sequenzen: Fol. 172v Alia de S. Spiritu: Festum paracliti omnis recolet populus. ${ }^{60}$ Für das Fronleichnamsfest ist an erster Stelle die bekannte Sequenz Lauda Sion und danach noch drei andere: Fol. 176r-179r, Verbum patris incarnatum, ${ }^{61}$ weiter $O$ panis dulcissime,${ }^{62}$ das aus Süddeutschland um die Wende des 13./14. Jahrhunderts stammt, und drittens Ave caro Christi regis. ${ }^{63}$ Es erhielten sich alle Marienmessen im Verlauf des Jahres, d. h. Samstagsvotivmessen und die sog. Alltagsmaturamessen. Auch noch beide Pro defunctis Messen stehen hier zur Verfügung.

An liturgischen Zusätzen ist dieses Graduale arm. Es gibt im Graduale nur dreizehn datierte Erinnerungseinträge, beginnend mit 1516 bis hin zu 1657, auf die an den Betrieb des Graduale hinweisen.

57 Vgl.z.B. Fol. 89r Am Dienstag der Osterwoche gibt es Alleluia Nonne cor nostrum nach Handschriften der Vorreformzeit.

58 Op. cit. SCHLAGER, 1987, S. 839-879.

59 DREVES, Guido Maria. Analecta hymnica medii aevi Bd. 10. Liturgische Prosen des Mittelalters. Leipzig 1891, S. 66, Num. 78 mit dem frühesten Eitrag in einem Sammelband S. Clare Crumloviensis saec. 15. ex, Národní knihovna české republiky Praha (weiter PNk) XII A 17.

60 BLUME, Clemens. Analecta hymnica medii aevi Bd. 42. Liturgische Prosen des Mittelaters. Leipzig 1903, S. 39, Num. 26, am frühesten im Graduale, PNm XIII A 2, datiert 1512.

61 DREVES, Guido Maria. Analecta hymnica medii aevi Bd. 9. Liturgische Prosen des Mittelalers. Leipzig 1890 , S. 32, Num. 45, am frühesten im Graduale aus Jistebnice, PNm XII F 14.

62 AH 54, op. cit., S. 259, Num. 169, am frühesten auch im Graduale PNm XII F 14 geschrieben wurde

63 AH 54, op. cit., S. 261, Num. 170, am frühesten im Missale des Prager Bischofs Jan z Dražic, PNm XIII B 9 geschrieben wurde. Die bei Utraquisten beliebten Sequenzen Vebum Patris incarnatum und O pannis dulcissime stehen dem maßgebenden Missale Olomucense 1488 außerhalb, vgl. op. cit. Anm. 42. 
Velká Bíteš war eine Untertanenstadt, die die Hussitischen Kriege ohne größere Schäden überlebte. Nach Jan Tiray, dem Historiker von Velká Bíteš, ${ }^{64}$ entwickelte sich in der zweiten Hälfte des 15. Jahrhunderts die Stadt sowohl wirtschaftlich, als auch religiös fort. Vor allem in der Zeit der Herrscherfamilie von Lomnitz (z Lomnice; 1480-1567) und dann unter der Adelsfamilie von Zerotein (z Žerotína; 1567-1623). Die reichen Stadtbürger unterstützten mittels Stiftungen ihre Kirche und auch die soziale Sphäre. Schon 1468 gründete Martin der Müller eine Morgenmessestiftung. ${ }^{65}$ Dorota Hladká 1485 erweiterte diese Stiftung auf samstags Marienvotivmessen und samstags Vespergesänge, der der städtische Schulmeister mit seinen Sängerknaben singen sollte. Auch Totenmessenstiftungen waren häufig. ${ }^{66}$ Es wurden neue Altäre in St. Johannes Stadtkirche gestiftet (z.B. 1505 des hl. Kreuzes), und nötige Bücher (1499 Missale Olomucense), neue Glocken und Kirchen-Requisiten gekauft. ${ }^{67}$ Der Verfasser des neuen Graduales vom Ende des 15. Jahrhunderts ist jedoch nicht bekannt. Das Besitzerrecht der Kirche besaßen schon im 13. Jahrhundert die Zisterzienserinnen von Tišnov. Bis 1500 war Bíteš rein katholisch. In der ersten Hälfte des 16. Jahrhunderts beginnen die Utraquisten ihre Rolle zu spielen, und um die Mitte dieses Jahrhunderts ist nur katholische Minderheit geblieben; es überwogen Utraquisten, dann Lutheraner und später auch Böhmische Brüder. ${ }^{68}$ In 1557 wirkte der erste Prediger Filip und die Zisterzienserinnen mussten das Besitzerrecht der Stadtgemeinde verpfänden. ${ }^{69}$ Erst am Anfang des 17. Jahrhunderts (1604) begann die katholische Kirche mit großen Problemen um ihre Rechte zu kämpften. Nach der Schlacht auf dem Weißen Berg wurde erst im Jahre 1626 ein katholischer Priester von dem Stadtrat akzeptiert. ${ }^{70}$

Es bleibt fraglich, welche Ergebnisse aus der gründlichen Analyse aller vier Gradualien gezogen werden können. Dem Inhalt nach sind die Gradualien der lateinischen Utraquisten fast dieselben, wie die der Katholiken. Es gibt nur einige Unterschiede: Schon die Hussiten im Jistebniczer Gesangbuch lassen den Gradualegesang aus, was auch lateinischen und tschechischen Utraquisten fortsetzten. ${ }^{71}$ Von Zwischenlesungsgesängen nur Alleluia eventuell mit Sequenz, und in der Buß- und Fastenzeit nur Tractus geblieben. Das kommt aber in den beiden utraquistischen Handschriften nicht systematisch vor, jedes Graduale geht seinen eigenen Weg. ${ }^{72}$ Das entspricht auch den Verwaltungsbedingungen der utraquistischen Kirche in Mähren, die im 15. und 16. Jahrhundert die regelmäßige

64 TIRAY, Jan. Dějiny města Velké Bíteše, dil I. Velké Meziř́ičí 1882, S. 95-175.

65 Ibid., S. 104.

66 Ibid., S. 107.

67 Ibid., S. 117.

68 Ibid., S. 154-172.

69 Ibid., S. 157-167.

70 Ibid., S. 172.

71 Vgl. KOLÁR, Jaroslav - VIDMANOVÁ, Anežka - VLHOVÁ-WÖRNER, Hana. Jistebnický kancionál MS. Praha, Knihovna Národního muzea, sign. II C 7. Kritická edice. I. svazek Graduale. Praha 2005, S. 86. Vgl. auch ŽŮREK, op. cit., 2011, S. 9-12.

72 Vgl. OREL, op. cit., 1922, S. 35, 36, 50 und 51, in dem bemerkte er dasselbe. Vgl. auch op. cit. ŽŮREK, 2011, S. 15 . 
Verwaltung und infolge dessen auch die Liturgiefürsorge entbehrte. ${ }^{73}$ In Mähren setzte sich schrittweise die kirchliche Verwaltung der Laien durch, wie oben die Quellen aus Moravská Třebová und Velká Bíteš anführen. ${ }^{74}$

In den Temporalen aller Gradualien interessiert uns vor allem der Stand der Fronleichnamsgesänge. ${ }^{75}$ Im utraquistischen Graduale aus Odry sind diese Teile ausgerissen, aber in seinem Kyriale sind die Cantiones Iesus Christus nostra salus (nur Text) und Vivus panis angelorum (zweistimmiges Cantio) geblieben. ${ }^{76} \mathrm{Im}$ Graduale aus Uherské Hradiště gibt es im Temporale nur die übliche Messe Cibavit eos, ${ }^{77}$ aber in einem mit derselben Hand geschriebenen Nachtrag wurden die Sequenz $O$ panis dulcissime, das Offertorium Sacerdotes incensum mit der Prosula Ave virgineum corpus domini geschrieben. ${ }^{78}$ Die Fronleichnamsmessgesänge im katholischen Graduale aus Moravská Třebová wurden ausgerissen, ${ }^{79}$ es wurde teilweise nur Messformular Cibavat eos und Sequenz Lauda Sion geblieben. Im Graduale aus Velká Bíteš die Fronleichnamsmesse im Temporale ausgerissen wird, aber im Sequenziar nach der üblichen Sequenz Lauda Sion wurden noch drei andere Sequenzen hinzugefügt: Verbum patris incarnatum, O panis dulcissime, Ave caro Christi. ${ }^{80}$ Wenn wir alle Fronleichnamsgesänge von vier Gradualien betrachten, gibt es die Werke des böhmischen Ursprungs im Mehrzahl: Iessus Christus nostra salus, Vivus panis angelorum, Verbum patris incarnatum, Ave caro Christi. Der erste und der letzte Gesang stammen noch aus vorhussitischer Zeit, zwei andere aus der zweiten Hälfte des 15. Jahrhunderts. Nur vereinzelt stammen die Werke aus Deutschland oder Österreich: O panis dulcissime, Ave virgineum corpus domini.

Beide Gradualien der lateinischen Utraquisten reduzieren streng die Sanctorale-Passage, aber man kann nicht feststehen, ob es aus dem theologischen, oder nur lokalen Grunde war. ${ }^{81}$ Für das Graduale aus Odry verwendete sein Schreiber als Vorlage ein altes Manuskript mit schwankender Olmützer liturgischer Tradition der Mitte des 14. Jahrhunderts. Ob er es aus einem theologischen Grunde absichtlich, oder nur zufälliger

73 Vgl. Kouřil, Miloš. Přrehled dějin církevni správy na Moravě od husitstvi do josefinských reforem. In XXVII. Mikulovské sympozium. Vývoj církevní správy na Moravě. Brno 2003, S. 7-30. Weiter auch ELBEL, Petr. Správa utrakvistické církve na Moravě mezi husitskou revoluci a reformací. In BOBKOVÁ, Lenka - KONVIČNÁ, Jana (eds.). Korunní zeměv dějinách českého státu. IV. Náboženský život a církevni poměry v zemich Koruny české ve 14 . -17. stoleti. Praha, 2009, S. 126-144.

74 Vgl. Anm. 53, 69, 70.

75 Die aufgehobene Eucharistieverehrung der zweiten Hälfte des 14. Jahrhunderts setzte noch im größeren Maße bei lateinischen Utraquisten der zweiten Hälfte des 15. Jahrhundert vor.

76 Vgl oben Anm. 8, 9.

77 Fol. 55r-56v Introitus Cibavit eos, Alleluia Caro mea, Sequenz (Fol. 103r-105r) Lauda Sion, Offertorium Sacerdotes incensum und Communio Quociescumque, vgl. Koncordanzen bei op. cit. VLHOVÁ, 1996, S. 34-36.

78 Vgl. Anm. 29.

79 Es blieb, Fol. 137r, nur die zweite Hälfte des Alleluia Caro mea, das Offertorium Sacerdotes incensum, im Vergleich mit dem Graduale aus Uh. Hradiště mit einer anderen Melodie versehen, und das Communio Quocies cumque. Im Sequenziar, Fol. 237v-238v, nur die übliche Sequenz Lauda Sion geblieben wurde.

80 Vgl. Anm. 61, 62, 63.

81 Die Hussiten entbehren ursprünglich die Verehrung der Heiligen. 
machte, kann man noch nicht feststellen. ${ }^{82}$ Es ist bemerkenswert, dass in allen Gradualien mit einziger Ausnahme mehrstimmige Werke fehlen, was aber mit dem allgemeinen Quellenstand der mehrstimmigen Musik in Mähren übereinstimmt. Es ist auch wichtig, dass es in den beiden Gradualien der Utraquisten nur den ornamentalen Bilderschmuck gibt und figurale Darstellungen fehlen. ${ }^{83}$

Am Ende machen wir noch eine kurze Übersicht über den liturgischen Betrieb aller Gradualien. Beide katholischen Gradualien verweisen in verschiedenen Zusätzen den Betrieb auch in der Lutherschen oder Böhmischen Reformation. Nach den Korrekturen im 17. Jahrhundert war die Rückkehr zum katholischen Gottesdienst merklich. Beide utraquistischen Gradualien bezeugen auch Verwendung im katholischen Gottesdienst des 17. Jahrhunderts. Zwei Gradualien aus den Städten mit deutscher Bevölkerung, Odry und Moravská Třebová, beinhalten mehr Zusätze aus der Lutherschen Reformation, im Graduale aus Moravská Třebová noch aus der Böhmischen Reformation. Im Graduale aus Odry wird in den Improperien am Karfreitag die Verteilung der singenden Personen von dem Hauptschreiber beschrieben. Im Graduale aus Moravská Třebová wurde noch in der ersten Hälfte des 16. Jahrhunderts die Verteilungen Literati - Chorus nachträglich notiert. Im Graduale aus Velká Bíteš sind es keine Verteilungen notiert, aber in den historischen Quellen vom Jahre 1485 wurde Kantor mit den Sängerknaben im Gottesdienste registriert. ${ }^{84}$ Alle diese Verteilungen weisen auf Existenz der lateinischen Schulen in den Städten hin. Im Graduale aus Odry wurde noch im 16. Jahrhundert die Verteilung Organist-Chorus in zwei Gloriagesänge angegeben, was noch auf die Existenz der Orgel hinweist. Alle diese Feststellungen weisen auf den Stand der lateinischen Messgesänge im 16. und 17. Jahrhundert in den Mährischen Untertanenstädten, in denen die Reformationsbewegung ihre Hauptstützpunkte hatte.

\section{Bibliography}

\section{Sources}

Graduale aus Odry 1504, Biskupství Ostrava, fond Odry, sign. A: 40/80112/20/0250.

Graduale aus Uherské Hradiště, Anfang des 16. Jahrhunderts, Vědecká knihovna Olomouc, sign. M II 398.

Gaduale aus Moravská Třebová, Ende des 15. Jahrhunderts, Muzeum Brněnska, Památník písemnictví na Moravě, Rajhrad, sign. R 627.

Graduale aus Velká Bíteš, Ende des 15. Jahrhunderts, Městské muzeum Velká Bíteš, sign. C 1/7.

Graduale et Kyriale cum sequenzen 1492-1493, Archiv města Brna, fond V 2, sign. 1 und 2.

Liber ordinarius ecclesiae Olomucensis 1376, Zemský archiv Opava, pobočka Olomouc, sbírka rukopisů Metropolitní kapituly sv. Václava v Olomouci, sign. CO 15.

82 Die Hussitische Kirche suchte die evangelische Reinheit ihrer Lehre im Vergangenheitsrückkehr.

83 Was kann man als Anklang an die hussittische Bilderstürmerei begreifen.

84 Vgl. Anm. 66. 
Messgesangbuch aus Kutná Hora, 15. Jahrhundert, Österreichische Nationalbibliothek Wien, sign. 15501.

HKm II A 6 Franus Gesangbuch aus 1505, Muzeum Východních Čech, Hradec Králové, sign. II A 6.

VBKk H 42 Gesangbuch Vyšší Brod aus 1410, Klášterní knihovna Vyšší Brod, sign. H 42.

PNm II C 7 Gesangbuch aus Jistebnice, nach 1430, Knihovna Národního muzea Praha, sign. II C 7 .

PNm XII F 14 Gradual aus Jistebnice, 2. Hälfte des 15. Jahrhunderts, Knihovna Národního muzea Praha, sign. XII F 14.

Vollmissale, erste Hälfte des 14. Jahrhunderts, Zemský archiv Opava, pobočka Olomouc, sbírka rukopisů Metropolitní kapituly sv. Václava v Olomouci, sign. CO 141.

PNm IV D 9 Liber ordinarius ecclesiae Pragensis, Knihovna Národního muzea Praha, sign XIV D 9.

Breviarium Pragense, zweite Hälfte des 14. Jahrhunderts, Wissenschaftliche Bibliothek Olmütz, sign. M I 719.

Sammelband von Joachim Cuonz 1506, St. Gallen, Stiftsbibliothek, Sign. 456.

Missale Olomucense 1488 Missale Olomucense, Bambergae, Johann Sensenschmidt imp. Petri Drach, IV. Non. Mart. [4. 3.] 1488.

Graduale 1550-1553, Muzeum Východních Čech, Hradec Králové, sign. Hr 57.

PNm XIII B 9 Missale des Bischofs Jan z Dražic, Knihovna Národního muzea Praha, sign. XIII B 9.

\section{Literature}

DREVES, Guido Maria. Analecta hymnica medii aevi Bd. 1. Cantiones Bohemice. Leiche, Lieder und Rufe des 13., 14., und 15. Jahrhundrts nach Handschriften aus Prag, Jistebnicz, Wittingau, Hohenfurt und Tegernsee. Leipzig 1886.

DREVES, Guido Maria. Analecta hymnica medii aevi Bd. 9. Liturgische Prosen des Mittelalers. Leipzig 1890.

DREVES, Guido Maria. Analecta hymnica medii aevi Bd. 10. Liturgische Prosen des Mittelalters. Leipzig 1891.

DREVES, Guido Maria. Analecta hymnica medii aevi Bd. 30. Pia dictamina. Reimgebete und Lieder des Mittelalters. Leipzig 1898.

BLUME, Clemens. Analecta hymnica medii aevi Bd. 42. Liturgische Prosen des Mittelaters. Leipzig 1903.

DREVES, Guido Maria. Analecta hymnica medii aevi Bd. 45b, Lider und Motetten des Mittelalters. Leipzig 1904.

BLUME, Clemens. Analecta hymnica medii aevi Bd. 49. Tropen des Missale im Mittelalter II. Tropen zum Proprium Missarum. Leipzig 1906.

AH 54

BLUME, Clemens - Bannister, Henry Marriott. Analecta hymnica medii aevi Bd. 54, Liturgische Prosen des Übergangsstiles und der zweiten Epoche. Leipzig 1914.

BOSSE, Detlev. Untersuchung einstimmiger mittelalterlichen Melodien zur Gloria in excelsis Deo. Regensburg 1955.

DOKOUPIL, Vladislav. Soupis rukopisu benediktinské knihovny v Rajhradě. Praha 1966.

ELBEL, Petr. Správa utrakvistické církve na Moravě mezi husitskou revoluci a reformací. In Bobková, Lenka-Konvičná, Jana (eds.). Korunní země v dějinách českého státu. IV. Náboženský život a církevní poměry v zemích Koruny české ve 14.-17. století. Praha 2009.

FOLTÝN, Dušan et al. Encyklopedie moravských a slezských klášterů. Praha 2005. 
GRAHAM, Barry Frederic Hunter. Bohemian and Moravian Graduals 1420-1620. Turnhout 2006.

GROLIG, Moritz. Die Bibliothek des Ladislaus von Bozkovicz (1485-1520) in Mährisch Trübau. Mitteilungen des österreichischen Vereines für Bibliothekswesen. 1904.

KOLÁR, Jaroslav -VIDMANOVÁ, Anežka - VLHOVÁ-WÖRNER, Hana. Jistebnický kancionál MS. Praha, Knihovna Národního muzea, II C 7. Kritická edice. I. svazek Graduale. Praha 2005.

KONRÁD, Karel. Dějiny posvátného zpě̃u staročeského od XV. věku do zrušeni literátských bratrstev. Praha 1893.

KOUŘIL, Miloš. Přehled dějin církevni správy na Moravě od husitstvi do josefinských reforem. In XXVII. Mikulovské sympozium. Vývoj církevní správy na Moravě. Brno 2003.

Kyriale seu ordinarium missae cum cantu gregoriano ex editione Vaticana adamussim excepto. Desclée et socii Parisiis, Tornaci, Romae 1920.

LIFKA, Bohumír. Staré knihovny v Moravské Třebové. In Pechová, Oliva (ed.). Moravská Třebová. Městská památková rezervace Státni památkové správy. Praha 1957.

MAŇAS, Vladimír. Náboženská bratrstva do josefinských reforem. In Jiránek, Tomáš - Kubeš, Jiří (edd.). Bratrstva. Světská a církevní sdružení a jejich role v kulturních a společenských strukturách od středověku do moderní doby. Pardubice 2005.

MELNICKI, Margareta. Das einstimmige Kyrie des lateinischen Mittealters. Regensburg 1955.

NEJEDLÝ, Zdeněk. Dějiny husitského zpěvu. Kniha třetí Jan Hus. Praha 1955.

OREL, Dobroslav. Kancionál Franusuv z roku 1505. Praha 1922.

POKORNÝ, František. Breviarium Pragense rukopisu M I 719 Státni vědecké knihovny v Olomouci. Studie o rukopisech 1971, roč. 10, s. 257-277.

ROLLEDER, Anton. Geschichte der Stadt und des Gerichtbezirkes Odrau. Steyer 1903.

RŮŽIČKA, Jindřich. Okresni archiv Svitavy se sidlem v Litomyšli. Prĩvodce po archivnich fondech a sbirkách. Praha 1973.

SCHILDBACH, Martin. Das einstimmige Agnus Dei und seine hanschriftliche Úberlieferung vom 10. bis zum 16. Jahrhundert. Erlangen 1967.

SCHLAGER, Karlheinz. Thematischer Katalog der ältesten Alleluia-Melodien aus Hanschriften des 10. und 11. Jahrhunderts, ausgenommen des ambrosianische, alt-römische und alt-spanische Repertoire. Verlegt bei Walter Riecke, München 1965.

SCHLAGER, Karlheinz. Monumenta monodica medii aevi, Bd. 8. Alleluia-Melodien ab 1100. Bärenreiter Kassel, Basel, London, New York 1987.

THANNABAUR, Peter Josef. Das einstimmige Sanctus der römischen Messe in der hanschriftichen Überlieferung vom 10. bis zum 16. Jahrhundert. Erlangen 1962.

TIRAY, Jan. Dějiny města Velké Biteše dil I. Velké Meziříčí 1882.

TOŠNEROVÁ, Marie. Rukopisné fondy muzei a galerii v České republice. Praha 2001.

TOŠNEROVÁ, Marie. Rukopisné fondy centrálnich a církevních knihoven v České republice. Praha 2004.

VLHOVÁ, Hana. Die Fronleichnamsmesse in Böhmen: Ein Beitrag zur spätmittelalterlichen Choraltradition. Schweizer Jahrbuch für Musikwissenschaft 1996, S. 13-36.

VLHOVÁ-WÖRNER, Hana. Tropi Ordinarii Missae, Pars III. Sanctus. Editio Bärenreiter Praha 2010. VLHOVÁ-WÖRNER. Tropi Ordinarii Missae, Pars IV. Agnus. Editio Bärenreiter Praha 2013.

ŽU゚REK, Jiří. Graduale Bohemorum, Proprium sanctorum. Praha 2011. 
